\title{
O tema da adolescência na saúde coletiva - revisitando 25 anos de publicações
}

\author{
Adolescence in public health - revisiting 25 years of publications
}

Simone Gonçalves de Assis (https://orcid.org/0000-0001-5460-6153) ${ }^{1}$

Joviana Quintes Avanci (https://orcid.org/0000-0001-7779-3991) ${ }^{1}$

Fernanda Serpeloni (https://orcid.org/0000-0001-6222-0162) ${ }^{1}$

${ }^{1}$ Departamento de Estudos sobre Violência e Saúde Jorge Careli, Escola Nacional de Saúde Pública Sérgio Aroouca, Fiocruz. Av. Brasil 4036/700,

Manguinhos. 21040-361

Rio de Janeiro RJ Brasil.

simone.assis@fiocruz.br

\begin{abstract}
This study aims to develop scientific knowledge on adolescence in publications from 1996 to 2020 in Journal Ciência \& Saúde Coletiva. This integrative systematic review was based on a bibliographic survey in SciELO's database, with the string word search strategy "Adolesc \$" in title, abstract, and keywords of works published in the C\&SC between 1996 and 2020. The abstracts of 432 publications were analyzed by age group, gender, skin color, social stratum, sample, place, methodology, and risk and protective factors. The results show that most of the abstracts brought studies exclusively focused on the adolescent population, with a smaller volume on children or adults. Most of the samples were collected in schools, followed by health services. The topics addressed in the papers are related to adolescents' individual attributes, family attributes, peer relationships; social scope, health conditions and diseases, accidents and violence, and health services. There is a need for special attention to adolescents' health requiring reflections in national academic production, aiming at systemic and complex knowledge focused on adolescent health promotion aspects, following the existing national legislation and laws.
\end{abstract}

Key words Adolescence, Integrative review, $\mathrm{Pu}$ blic health
Resumo Busca-se compreender o desenvolvimento do conhecimento científico sobre a adolescência expresso em publicações dos anos de 1996 a 2020 da revista Revista Ciência \& Saúde Coletiva (C\&SC). O estudo de revisão sistemática integrativa foi feito a partir de levantamento bibliográfico no SciELO com a estratégia de busca: "Adolesc\$" em título, resumo e palavras-chave nos artigos da C\&SC publicados entre 1996 e 2020. Resumos de 432 publicações foram analisados segundo faixa etária, sexo/ gênero, cor da pele, estrato social, amostra, local, metodologia e fatores de risco/proteção. Os resultados mostram que grande parte volta-se exclusivamente para a adolescência e em menor quantidade infância ou vida adulta. Grande parte dos estudos foi realizada com amostras de adolescentes nas escolas, seguida por serviços de saúde. Os temas abordados nas publicações são: atributos individuais dos adolescentes; atributos familiares; relações entre pares; abrangência social; condições de saúde e doenças; acidentes e violências; e atuação profissional e de serviços. Constata-se a necessidade de atenção especial para a saúde dos adolescentes, que precisa estar refletida na produção acadêmica nacional, visando o conhecimento sistêmico, complexo e que se volte para a promoção à saúde dos adolescentes, acompanhando as normativas e leis nacionais existentes.

Palavras-chave Adolescência, Revisão integrativa, Saúde pública 


\section{Introdução}

Muito se escreveu e se pensou sobre a adolescência e o ser adolescente nos últimos 25 anos na área da saúde coletiva, através do enfoque multidisciplinar da demografia, epidemiologia sociologia, antropologia, psicologia e medicina, em especial, enriquecendo o entendimento desta particular fase da vida. Uma das grandes guinadas do conhecimento científico sobre o tema neste período foi o seu reconhecimento como um momento de oportunidade única, que carrega os ganhos obtidos da primeira infância e, em alguns casos, provê uma segunda chance à promoção $\mathrm{e}$ ao fortalecimento do bem-estar e da saúde, que trarão consequências para a vida adulta e a próxima geração ${ }^{1}$.

Tradicionalmente, a adolescência é definida pela segunda década da vida, estendendo-se dos 10 aos 19 anos, sendo marcada por um complexo processo de crescimento e desenvolvimento biopsicossocial, manifestado através de transformações anatômicas, fisiológicas, psicológicas e sociais ${ }^{2}$. Sob a perspectiva da legislação brasileira, o Estatuto da Criança e do Adolescente considera adolescente todo indivíduo com idade entre $12 \mathrm{e}$ 18 anos $^{3}$. Contudo, é reducionista compreender este período da vida sob um critério exclusivamente cronológico, pois se caracteriza por ser uma etapa plural, quando as experiências e os contextos, com suas particularidades, os recursos existentes e os acionados são distintos segundo grupos sociais, gerando diferentes conceituações e compreensões do que é ser adolescente.

A Organização Mundial da Saúde (OMS) destaca que, apesar dos avanços na sáude dos adolescentes em países europeus nas últimas décadas, persistem disparidades entre e dentro dos países e em determinados grupos populacionais ${ }^{1}$. No Brasil, a população estimada de adolescentes é de 21 milhões ( $11 \%$ do total). O país é ainda um dos países mais desiguais do mundo, o que expõe o adolescente a uma situação de muita vulnerabilidade. Segundo dados do Fundo das Nações Unidas para a Infância, o Brasil é o país com o maior número absoluto de adolescentes assassinados no mundo. Em 2015, foram 11.403 vítimas de homicídios entre 10 e 19 anos, muito mais frequente entre os negros. O número é maior do que o total de mortes violentas de meninos em países afetados por conflitos, como Síria e Iraque. Ainda cerca de 30 mil adolescentes recebem medidas de privação de liberdade a cada ano ${ }^{4}$. Na educação, em 2017, 12,8\% dos adolescentes entre 15 e 17 anos estavam fora da escola; $28,2 \%$ tinham uma distorção idade-série de dois anos no Ensino Médio, com destaque para as Regiões Norte $(41,4 \%)$ e Nordeste $(36,2 \%)$ do país; e, segundo dados do Instituto Nacional de Estudos e Pesquisas Educacionais/Ministério da Educação, em 2017, 6,1\% abandonaram o Ensino Médio devido a pobreza, violência e gravidez, principais motivos de evasão. A taxa de gestação na adolescência no Brasil é alta para a América Latina, com 400 mil casos/ ano 5 . O cenário de pobreza, exploração sexual e do trabalho, violências (psicológica, física, sexual e negligência), uso de álcool e drogas, problemas de saúde mental, relação sexual desprotegida e bullying compõe os agravos que mais acometem esta fase da vida ${ }^{6}$.

O Brasil tem uma das legislações mais avançadas do mundo no que diz respeito à proteção da infância e da adolescência, embora as políticas públicas específicas para o cuidado e a atenção aos adolescentes ainda necessitem ser aprimoradas para atingir as especificidades deste grupo social. Historicamente, as políticas públicas em saúde sempre estiveram vinculadas à gestão da vida em idade $e^{7}$ e as relacionadas aos adolescentes estão ligadas aos significados sociais deste grupo etário. É na década de 1970 que surgem os primeiros serviços voltados especificamente para essa população, com caráter assistencial e associado às universidades. A partir da década de 1980, surgiram comitês que se preocupavam com a saúde do adolescente, o que impulsionou um olhar particularizado para este grupo populacional e uma pressão para incluí-lo nas políticas públicas, com um esforço em desmitificar sua concepção vinculada à criminalização e violência $^{7}$. Em 1986, o Ministério da Saúde englobou a assistência primária à saúde desta população com foco naqueles em risco social e privilegiando as questões das doenças sexualmente transmissíveis, HIV e AIDS, uso de drogas, acidentes de trânsito e gravidez precoce ${ }^{8}$. Foi nesta época que se elaborou a primeira política de saúde criada especificamente para o adolescente - o Programa Saúde do Adolescente (PROSAD), em 1989, em decorrência da 42a Assembléia Mundial de Saúde, promovida pela OMS. O PROSAD representou avanço importante em termos de saúde pública voltada para esta população e tinha a proposta de atenção integral, sobretudo na atenção primária ${ }^{9}$.

A década de 1990 caracterizou-se como um marco para as políticas públicas voltadas para os adolescentes, com a criação do Estatuto da Criança e do Adolescente 3 , que, juntamente com os ordenamentos jurídicos da Constituição Federal de 1988 e as Leis Orgânicas de Saúde, pro- 
porcionou a legitimação de novo paradigma e compreensão do adolescente na sociedade. Os adolescentes passaram a ser considerados sujeitos sociais e autônomos, devendo ser inseridos nas decisões do Estado ${ }^{9,10}$. No período entre 1995 e 2002 houve incremento das políticas públicas dirigidas aos adolescentes e jovens, mas ainda com ações muito voltadas à criminalidade a partir de uma perspectiva de salvação dos riscos relacionados ao crime, ao tráfico e à violência ${ }^{9,11}$.

O Programa Saúde do Adolescente ${ }^{12}$ foi um marco para as políticas públicas no país, culminando com a Política Nacional de Atenção Integral à Saúde do Adolescente e Jovem ${ }^{13}$, que suscitou diretrizes e orientações específicas para os adolescentes em nível nacional ${ }^{14,15}$ e tornou-se a base da reflexão sobre a atenção à saúde do adolescente hoje existente. Essa política pressupôs o atendimento integral com prioridade para as atividades preventivas, sem prejuízo dos serviços assistenciais, e a organização de serviços para a execução dessas práticas de saúde, destacando a importância da promoção da saúde e a necessidade de estabelecer processos de trabalho intersetoriais e interdisciplinares. $\mathrm{O}$ enfoque passou a ser a promoção da saúde e o protagonismo juvenil, tendo como questões prioritárias: o crescimento e o desenvolvimento saudáveis, a saúde sexual e reprodutiva, e a redução da morbimortalidade por violências e acidentes. Também nesta época foi lançada a Política Nacional de Juventude, com foco em jovens de 15 a 29 anos, ressaltando a juventude como segmento social estratégico ${ }^{11,16}$. Outros programas foram fundamentais para a melhoria da saúde desta população, como: Rede Cegonha, Programa Nacional de Alimentação Escolar (Pnae), expansão da Estratégia Saúde da Família, Programa Mais Médicos, Bolsa Família, Programa Saúde na Escola (articulação de ações das equipes de atenção básica e educação), Plano Juventude VIVA (enfrentamento dos homicídios contra jovens negros), a estruturação da Vigilancia de Violências e Acidentes (VIVA) e a notificação compulsória das violências domésticas, além da implantação de redes de proteção à infância e adolescência. A Política Nacional de Atenção Integral à Saúde de Adolescentes em Conflito com a Lei (PNAISARI) é um avanço para o cuidado deste grupo específico de adolescentes ${ }^{17}$.

De forma sintética, este percurso histórico mostra a concepção inicial, que ainda permanece, de adolescência como a idade de risco, muito associada a problemas sociais e a cometimento de atos infracionais, o que justifica o uso de estratégias de controle, que vêm lentamente se trans- formando em abordagem voltada para uma visão mais positiva, de protagonismo e autonomia ${ }^{7,18}$. Ainda é grande a falta de valorização dos aspectos culturais, sociais e subjetivos vividos pelos adolescentes, frequentemente não considerados no planejamento das ações em saúde ${ }^{19}$.

A trajetória histórica dos principais temas, políticas e ações voltadas para a população adolescente no Brasil fundamentam a pergunta central que move o artigo que é compreender o desenvolvimento do conhecimento científico sobre o tema da adolescência expresso em publicações dos anos de 1996 a 2020 da revista Revista Ciência \& Saúde Coletiva (C\&SC).

\section{Métodos}

Trata-se de um estudo de revisão integrativa cujo método consiste em uma síntese dos achados apresentados pelas pesquisas sobre determinado tema, possibilitando análise ampliada acerca da produção do conhecimento do tema investigado, no caso adolescência, bem como a identificação de lacunas existentes ${ }^{20}$.

Realizou-se busca bibliográfica na base SciELO (17 de março de 2020) com a seguinte estratégia de busca: “Adolesc\$”, localizada em título, resumo e palavras-chave apenas em artigos da Revista Ciência \& Saúde Coletiva publicados nos últimos 25 anos (1996-2020). Os seguintes critérios de exclusão foram definidos: (1) não investigar, priorizar ou ser dirigido para a faixa etária da adolescência. Alguns poucos artigos, embora se dirigissem à adolescência, foram excluídos por terem foco voltado para adultos/instituições que lidam com essa faixa etária; (2) o tipo de material (press release e resenha de livro); e (3) outros motivos. A decisão pela exclusão dos artigos foi realizada através de consenso por pelo menos dois pesquisadores.

Identificaram-se 969 artigos científicos, dos quais 484 foram excluídos por duplicidade. Os resumos das 485 publicações foram analisados a partir de uma planilha em excel, compondo os resultados apresentados na Figura 1, onde nota-se que 53 trabalhos foram excluídos devido aos critérios adotados. Ao final, 432 publicações foram analisadas a partir dos resumos, segundo as categorias: faixa etária (criança+adolescente, adolescente, adolescente+adulto); tipo de amostra estudada (populacional, escolar, serviços de saúde, entre outros); local onde foi realizado o estudo; tipo de metodologia (transversal, coorte, qualitativo, teórico, revisão bibliográfica, análise 


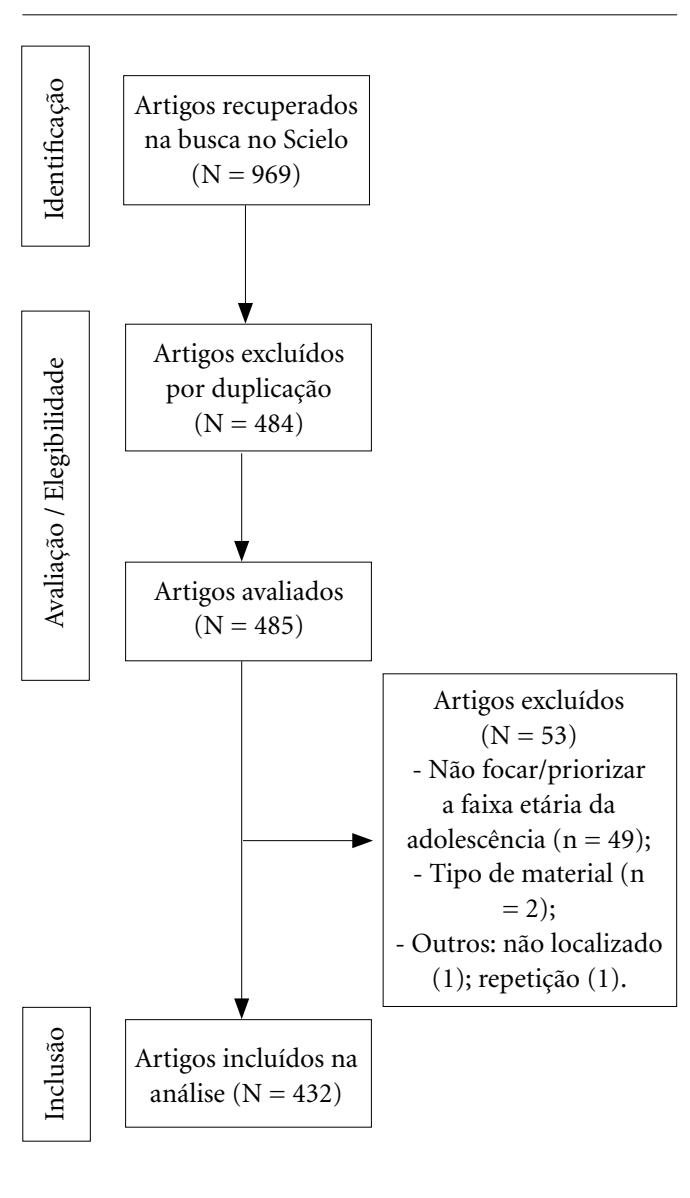

Figura 1. Fluxograma de identificação e seleção dos artigos sobre adolescência publicados na Revista Ciência \& Saúde Coletiva (1996 - 2020).

documental, entre outros); análise por sexo/gênero, por cor da pele e por estrato social; fator de risco e de proteção. Apenas em casos específicos, o texto era visualizado na íntegra para determinar sua elegibilidade.

Para a análise da inserção do tema da adolescência em relação a outros abordados na revista e a caracterização das publicações selecionadas, considerou-se a proporção do número de artigos aqui analisados (432) pelo número total de publicações da revista até março de 2020 (5.900), além da descrição das categorias segundo os três blocos temporais (de oito anos): 1996-2003, 2004-2011 e 2012-2019. O ano de 2020 foi considerado separadamente uma vez que foram incluídos apenas os resumos publicados nos três primeiros meses do ano.
Foi feita uma análise dos temas mais comuns abordados nos títulos dos artigos, que foram categorizados em recorrentes e pontuais (citados mais e menos de cinco vezes ao longo dos anos, respectivamente), sendo criada uma nuvem de palavras, ou seja, um gráfico digital para análise qualitativa dos dados que mostra o grau de frequência das palavras em um texto. Quanto mais a palavra é utilizada, mais chamativa é a representação dessa palavra no gráfico ${ }^{21}$. Foram incluídas as palavras recorrentes dos títulos em português, totalizando 148 palavras. Foram excluídos os artigos, pronomes e conjunções. O gráfico foi elaborado utilizando-se o programa de visualização de dados Tableau ${ }^{22}$.

Foi também realizada uma análise qualitativa dos principais assuntos existentes nos resumos, podendo haver mais de uma temática por artigo. Foram apontados os fatores de risco e proteção abordados. Toda a análise foi realizada segundo os três blocos temporais. Os resultados estão categorizados da seguinte forma: (1) atributos individuais dos adolescentes; (2) atributos familiares; (3) relações entre pares; (4) abrangência social; (5) condições de saúde e doenças; (6) acidentes e violências; (7) atuação profissional e de serviços; e (8) outras.

\section{Resultados}

\section{Artigos sobre o tema da adolescência na Revista Ciência \& Saúde Coletiva (C\&SC)}

A revista C\&SC começou a ser publicada em 1996 com um fascículo por ano, aumentando progressivamente até tornar-se mensal em 2011. Dentre o total de 432 artigos selecionados temse que $7,3 \%$ de artigos publicados pela revista durante os 25 anos focou na temática. Embora apenas em 1999 tenha sido publicado o primeiro estudo com foco no tema do adolescente, observa-se crescente aumento no número de publicações ao longo dos anos (Figura 2). No primeiro período (1996-2003) a revista publicou 367 artigos incluindo todas as temáticas e 18 sobre adolescentes (4,9\%); no segundo (2004-2011) foram 2.109 artigos sendo 136 de adolescentes (6.2\%); já no terceiro período (2012-2019) existiram 3.312 artigos no total e 271 de adolescentes $(8,2 \%)$. Constata-se que no último período o número absoluto de artigos sobre o tema é 15 vezes maior do que no primeiro, bem como aumento proporcional, comprovando o crescente interesse no tema. Essa evolução crescente parece se man- 


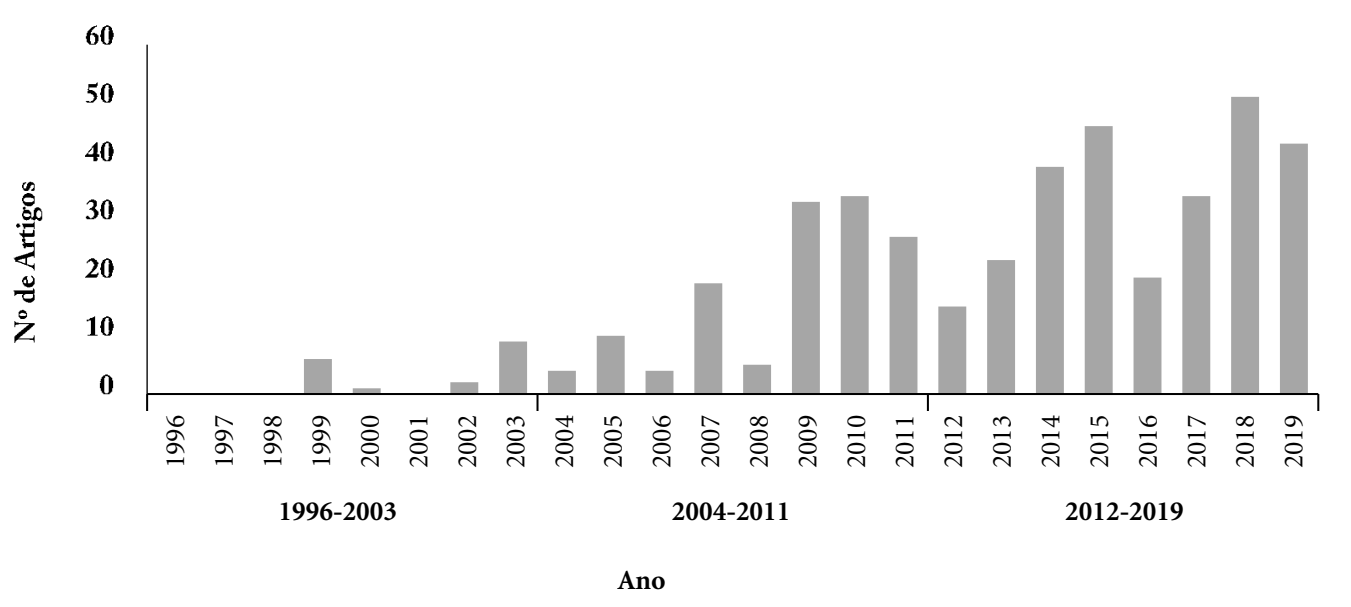

Figura 2. Número absoluto de artigos voltados para a população adolescente publicados por ano e por período na revista Ciência \& Saúde Coletiva, 1996 a 2019*.

*O número mínimo de publicações é igual a zero (1996, 1997, 1998 e 2001) e o número máximo 51 (2018).

ter no ano de 2020, uma vez que nos três primeiros meses do ano sete artigos sobre adolescentes foram publicados nos três volumes da revista.

\section{Caracterização das publicações}

Dentre os 432 estudos analisados, grande parte volta-se exclusivamente para a população adolescente $(68 \%)$. Uma parcela menor reuniu a temática numa abordagem da criança e do adolescente $(22 \%)$ e apenas um pequeno número incluiu também adultos (2\%). Na análise por período, a quantidade de trabalhos com foco exclusivo na adolescência foi aumentando no decorrer dos anos, $55 \%$ no primeiro período para $72 \%$ no terceiro. Inversamente, aqueles que incluíam crianças e adolescentes foram diminuindo, de $44 \%$ no primeiro período para $16 \%$ no segundo, o que sugere aumento da projeção de estudos voltados para as particularidades da adolescência enquanto campo específico.

Grande parte dos estudos foram realizados com amostras de adolescentes no ambiente escolar $(28 \%)$, seguida por serviços hospitalares ou de saúde (19\%). Trabalhos voltados à população geral $(12 \%)$ e a jovens em conflito com a lei $(3 \%)$ também foram mencionados em menor proporção. Houve aumento do número de estudos com adolescentes em escolas do primeiro período (17\%) para o terceiro período (29\%). Já em rela- ção aos adolescentes em conflito com a lei, houve descréscimo do primeiro período (11\%) para o terceiro (1\%). Em geral, grande parte da amostra é de adolescentes brasileiros. Entre os resumos selecionados $4 \%$ são de estudos que envolvem populações internacionais. Os países estudados foram: México (o mais citado), Argentina, Estados Unidos, Portugal, Cabo Verde, Chile e Espanha. Dentre todos os estudos realizados no Brasil, 7\% apresentam dados com representatividade de todo o território nacional.

Quanto ao desenho metodológico, mais da metade dos artigos sobre adolescentes baseiase em metodologia quantitativa $(55,8 \%)$, com destaque para os inquéritos epidemiológicos $(39,3 \%)$; seguido por estudos com metodologia qualitativa (17,3\%), revisão bibliográfica $(10,1 \%)$ e, em menor escala, os eminentemente descritivos (baseados em dados secundários), os teóricos, os quantitativos-qualitativos, os de validação de escala, os de intervenção e os estudo de caso. No decorrer dos três períodos (1996-2003, 2004 2011 e 2012-2019) houve aumento no número de artigos publicados com metodologia quantitativa: $17 \%$ no primeiro período, $50 \%$ no segundo e $60 \%$ no terceiro. O mesmo não ocorreu entre os estudos qualitativos, com variação discreta ao longo dos períodos, $11 \%$, 24\% e 14\% respectivamente. $\mathrm{O}$ número de trabalhos que mencionam abordagem de métodos quantitativos e qualita- 
tivos sobre o tema da adolescência apresentaram redução ao longo do tempo $17 \%, 3 \%$ e $2 \%$.

Quase metade dos resumos apresentava análises por sexo ou gênero, mas poucos se dedicavam ao aprofundamento das particularidades de apenas um deles. Quando essa especificidade ocorreu, o gênero feminino prevaleceu. A análise por cor da pele dos adolescentes é ainda mais incipiente ( $3 \%$ dos resumos trazem esta apreciação). A referência à população LGBTI+ apareceu em menos de $1 \%$ dos estudos sobre adolescentes, apenas depois do ano 2004. Com relação ao estrato social, aproximadamente $15 \%$ dos estudos informaram essa análise.

\section{Temáticas sobre a adolescência}

Ao analisar os títulos das publicações, constatase que as dez palavras que aparecem com maior frequência em ordem decrescente são: adolescentes, saúde, Brasil, crianças, fatores, escolares, violência, estudo, associados e brasileiros. Entre as palavras com menos repetições são: cuidado, homens, indicadores, mães, sobrepeso, reprodutiva, odontológica e transtornos (Figura 3). No período 1996-2003, as palavras que se destacam são: saúde, adolescentes, criança e prevenção. No segundo período (2004-2012), as 10 primeiras palavras mais frequentes são: adolescentes, saúde, crianças, violência, escolar, Brasil, estudo, social, fatores. Já no terceiro período (2013-2019), as dez primeiras palavras mais citadas são: adolescentes, saúde, Brasil, fatores, escolar, associados, crianças, estudo e violência. As palavras adolescentes, saúde, violência e crianças foram recorrentes nos três períodos. Como é possível observar na nuvem de palavras (Figura 3), a análise dos títulos mostra que os temas e/ou contextos citados com maior frequência nos artigos sobre adolescentes ao longo dos 25 anos da C\&SC estão relacionados à saúde, violência, criança e escolar, com ênfase no contexto brasileiro. As palavras maiores apresentam mais repetições nos títulos e as palavras menores têm menos frequência.

Sobre os estudos voltados para a violência, verifica-se que entre os anos 1996-2003, 61\% dos artigos publicados sobre os adolescentes trouxeram esse tema (11 artigos), o que aumentou de forma importante (sete vezes mais) no período 2012-2020 (77 artigos).

Em uma outra análise voltada para os temas abordados nos resumos das publicações, observase progressiva variabilidade de palavras ao longo do tempo, apontando para a maior diversidade temática e o aprofundamento de questões sobre a adolescência. São evidentes a predominância e a variedade de termos entre os anos de 2012 a 2020, a pouca variação observada entre 1996 e 2003 e o patamar intermediário constatado entre 2003 e 2011. O Quadro 1 mostra as principais categorias encontradas. Ressalta-se que um artigo pode estar inserido em mais de uma categoria na análise.

Dentre todas as temáticas mais enunciadas destacam-se especialmente: (1) alimentação/ nutrição, atividade física e gravidez, dentre os atributos individuais; (2) padrão socioeconômico/renda e qualidade de vida, na perspectiva da abrangência social; (3) uso de drogas, saúde/ doença bucal e obesidade/sobrepeso na categoria condições de saúde; (4) e diversos tipos de violência. Temas relacionados aos atributos familiares, às relações entre pares, à atuação profissional/de serviços de saúde e outras instituições são menos citados (Quadro 1).

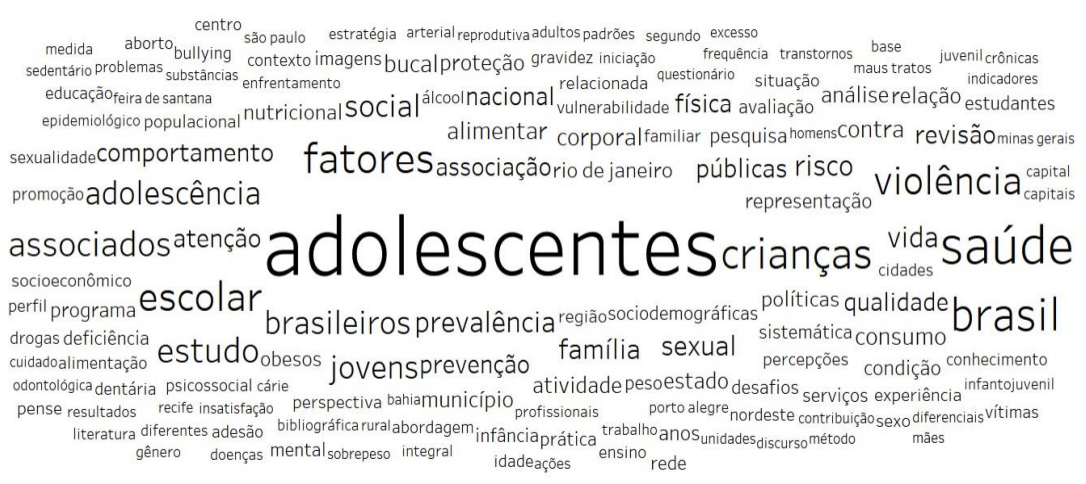

Figura 3. Palavras com maior frequência nos títulos das 432 publicações. 
Quadro 1. Principais temas abordados nas publicações analisadas*.

\begin{tabular}{|c|c|}
\hline Categorias & Temas \\
\hline $\begin{array}{l}\text { Atributos } \\
\text { individuais }\end{array}$ & $\begin{array}{l}\text { Temáticas recorrentes: alimentação, nutrição, transtornos alimentares, assistência nutricional (64); } \\
\text { atividade física/comportamento sedentário (43); gravidez (22); sexualidade (12); imagem corporal } \\
\text { (10); resiliência (8); religiosidade (7); aborto (7); negros (7); trabalho/exploração do trabalho (7); sexo } \\
\text { (6); faixa etária (6). } \\
\text { Temáticas pontuais: autoestima; adolescente em conflito com a lei; aleitamento materno exclusivo; } \\
\text { agressividade; autoconceito; autonomia / heteronomia; autopercepção negativa de saúde; baixa } \\
\text { escolaridade; bem-estar subjetivo; competência;cesária; coping; contracepção, métodos contraceptivos; } \\
\text { comportamento sexual; comportamento agressivo /antissocial; delinquência; desamparo; hábitos de } \\
\text { sono; higiene; homossexualidade; iniciação sexual; impulsividade; felicidade e otimismo; planejamento } \\
\text { familiar; pré-natal; rebeldia; marcas corporais; matar aula; relações de namoro; satisfação com a vida; } \\
\text { sentimento de tristeza; senso de coerência; solidão; uso de preservativos; valores sexuais. }\end{array}$ \\
\hline & $\begin{array}{l}\text { Temáticas pontuais: ausência paterna; paternidade na adolescência; comunicação pai-filho; composição } \\
\text { / estrutura; cuidado dos pais(falta de suporte, baixo "entendimento", intrusões dos pais na privacidade } \\
\text { do adolescente); casas com muitas pessoas; coesão familiar; conflito; comportamento positivo dos pais; } \\
\text { cuidados maternos; paternidade; escola de pais; escolaridade dos pais; gênero, masculino, agressor; } \\
\text { integração intergeracional; intervenção intergeracional; morar com os pais; "responsabilidade civil" e } \\
\text { "responsabilidade parental"; relacionamento; trabalho materno; supervisão familiar. }\end{array}$ \\
\hline $\begin{array}{l}\text { Relações entre } \\
\text { pares }\end{array}$ & $\begin{array}{l}\text { Temáticas pontuais: ausência de relação; comportamento prosocial; dificuldades / rejeição; pares } \\
\text { "desviantes"; relacionamento com pares; rede de amigos. }\end{array}$ \\
\hline & $\begin{array}{l}\text { Temáticas recorrentes: padrão socioeconômico/renda (24); qualidade de vida (18); mídia (jogos online, } \\
\text { tempo de uso de mídias sociais, rede social (13); Políticas (sociais, de equidade, de promoção da saúde, de } \\
\text { saúde mental, do adolescente (7). } \\
\text { Temáticas pontuais: apoio social; autopercepção de saúde / percepção de saúde; agenda } 2030 \text { - objetivos } \\
\text { do Desenvolvimento Sustentável-ODS; bolsa Família; capital social; conselho tutelar; contaminação } \\
\text { ambiental; desigualdade social; desemprego; direitos (sexuais e reprodutivos, crianças, à cidade); nível } \\
\text { educational; educação sexual; condições e estilos de vida; eventos estressantes / eventos de vida; fatores } \\
\text { sociodemográficos, ambientais e escolares; grupos vulneráveis; integração social da rede de proteção; } \\
\text { migração; local de residência; poluição do ar; pobreza; proteção social; polos de irrigação agrícola; } \\
\text { participaçao em atividades coletivas; projetos sociais; planejamento familiar; saúde mental; saúde sexual e } \\
\text { reprodutiva; morador de comunidade; segurança alimentar e nutricional; situação de rua; vulnerabilidade. }\end{array}$ \\
\hline Saúde/doença & $\begin{array}{l}\text { Temáticas recorrentes: uso de drogas - cigarro, álcool, crack, medicação e outras drogas (51); } \\
\text { saúde/doença bucal (39); obesidade/sobrepeso /transtorno alimentar (32); DST /HIV / AIDS (17); } \\
\text { deficiências (11); medicalização (11); saúde mental / problemas de saúde mental / transtornos } \\
\text { psiquiátricos (10); risco cardiovascular / metabólico(8); suicídio / tentativa / ideação, comportamento } \\
\text { suicida (8); depressão/ sintomas depressivos (7). } \\
\text { Temáticas pontuais: adesão a tratamento; assistência ventilatória; bruxismo; câncer; doenças } \\
\text { crônicas; deficiência de vitamina A; diabetes; dor de cabeça; dor lombar; escoliose idiopática; fatores } \\
\text { de proteção e risco para doenças não transmissíveis; doenças crônicas; espinha bífida; escoliose; } \\
\text { osteogênese imperfeita; fibrose cística; hipermetropia; hiperatividade; insônia; paralisia cerebral; } \\
\text { problemas comportamentais; problema oftalmológico; estresse; cuidados de saúde; saúde em geral, } \\
\text { escolar, alimentar, do adolescente; síndrome de Down; tratamento oncológico; transtorno de estresse } \\
\text { pós-traumático; vacinação. }\end{array}$ \\
\hline $\begin{array}{l}\text { Acidentes e } \\
\text { violências }\end{array}$ & $\begin{array}{l}\text { Temáticas recorrentes: violência - autoinflingida, interpessoal, entre namorados, na escola, familiar, } \\
\text { comunitária, física, psicológica (46); bullying (12); violência / coerção /exploração sexual (15). } \\
\text { Temáticas pontuais: abandono; acidente de trânsito / transporte; agressão com armas - branca e de } \\
\text { fogo; causas externas; comportamento violento; exposição a agrotóxicos; maus-tratos; negligência; } \\
\text { notificação de violência; quedas; roubo, segurança; violência e cortisol; tráfico de pessoas. }\end{array}$ \\
\hline $\begin{array}{l}\text { Atuação } \\
\text { profissional/ } \\
\text { de serviços de } \\
\text { saúde e outras } \\
\text { instituições }\end{array}$ & $\begin{array}{l}\text { Temáticas pontuais: abrigos / serviços de acolhimento e reintegração familiar; escola; atendimento/ } \\
\text { uso SS; atendimento público; atuação institucional: CAPSi, ESF; desconhecimento sobre o modo } \\
\text { de cuidado; desarticulação da rede; profissional de família na comunidade; profissionais de } \\
\text { fonoaudiologia; problemas relacionados ao processo de trabalho; rede de atenção psicossocial; } \\
\text { vigilância em saúde e de acidentes e violências. }\end{array}$ \\
\hline Outros temas & $\begin{array}{l}\text { Temáticas recorrentes: validação / apresentação de escalas psicométricas (7); } \\
\text { Temáticas pontuais: área urbana/rural; avaliação; educação em saúde; prevenção; subjetividade e } \\
\text { cultura; representações sociais. }\end{array}$ \\
\hline
\end{tabular}

${ }^{\star}$ Os números entre parênteses nos temas recorrentes se referem a quantidade de vezes encontradas. Temas pontuais foram verificados em 6 ou menos documentos. 
Ao longo da existência da Revista C\&SC oito números temáticos sobre o tema da adolescência foram publicados, o que corresponde a $4,5 \%$ do total de 176 edições da revista até março de 2020. Cada volume possui editoriais e artigos específicos sobre o tema abordado. A opção por números temáticos reflete a demanda de publicações que chegam à revista, sendo também uma forma de indução de reflexões relevantes para a área. Três números temáticos foram organizados conjuntamente por pesquisadores brasileiros, canadenses, e portugueses, evidenciando a busca da internacionalização de pesquisa (v.12, n.5, 2007; v.19, n.3, 2014; v.23, n.9, 2018).

Os dados apresentados no Quadro 2 restringem-se aos que compõem o núcleo da revista sobre o tema da adolescência, excluindo aqueles de temas livres publicados ao final de cada edição. Todas as produções apresentadas nos números temáticos são do final da década de $2000 \mathrm{em}$ diante. Dois outros números temáticos abordam a faixa etária sob o prisma da escola e não são detalhados, o que aborda a Pesquisa Nacional de Saúde do Escolar - PeNSE (v.15, n.0, S2, 2010) e o Programa Nacional de Alimentação Escolar: limites e possibilidades para uma alimentação saudável (v.18, n.4, 2013).

As temáticas se diversificam entre 2007 e 2019, adequando-se a multidisciplinaridade da saúde pública, ponto forte da revista investigada. Em 2007 a prioridade do editorial foi a importância da interação entre meio social, família e indivíduo, a relevância da integridade física e emocional e a ação de serviços e da família no cuidado da criança e do adolescente. O tema da qualidade de vida se mostra presente desde este ano e se manterá constante em publicações posteriores. $\mathrm{O}$ tema da resiliência surge no editorial, embora ainda estivesse em fase inicial de sua incorporação no cenário brasileiro. Em 2009 o editorial privilegia a saúde mental de crianças e adolescentes. Faz críticas às políticas de saúde mental para a faixa etária, pouco estruturadas e disseminadas, bem como para a precária formação profissional. Os editores demandam a implementação de rede assistencial com base comunitária e de melhorias no modelo de assistência em saúde mental para a faixa etária. A violência e os eventos adversos que prejudicam a saúde mental são apontados.

Em 2011 priorizam-se os profissionais que trabalham com crianças e adolescentes, buscando articular diferentes abordagens metodológicas, saberes e regiões do país. O desenvolvimento desde o nascimento pré-termo à adolescência foi buscado e educação em saúde, avaliação de programas de assistência à saúde e humanização se destacam. Reforçou-se a interação do biológico e do ambiental. As condições de saúde e de vida foram objeto de análise no editorial de 2014, comparando-se contextos culturais semelhantes e diferentes dentro e fora do país, apontando-se a relevância das políticas, dos programas e dos projetos sobre proteção e prevenção de doenças e agravos para pessoas em situação de pobreza.

Em 2015 duas revistas foram lançadas. A primeira delas (v.20, n.1) salienta as desigualdades sociais e a cultura de violência que constituem risco para delinquência, agressões, mortes e institucionalização de crianças e adolescentes. A qualidade de vida é nomeada como elemento central. Violências e riscos psicossociais, homicídios e suicídios são apontados como questões cruciais. A segunda revista publicada este ano é a primeira exclusivamente voltada para o adolescente (v20, n.11), apontando questões relevantes em nível físico e emocional, como desenvolvimento físico, alimentação, saúde oral, qualidade de vida, vida escolar, profissionalização, desigualdade social, problemas de saúde mental (depressão, bullying, uso abusivo de drogas), violências, situação de rua, exploração do trabalho, doenças sexualmente transmissíveis e gestações não planejadas. $\mathrm{O}$ tema da masculinidade é ineditamente abordado no editorial. São recomendadas ações de prevenção e de promoção de saúde, além da participação e do protagonismo juvenil visando o autocuidado em saúde. Os editores consideram que o "sistema de saúde deve ver como uma de suas missões, ajudar a tirar a adolescência do lugar de bode expiatório dos problemas sociais" ${ }^{23}$.

Em 2018 um volume é integralmente destinado a adolescência e juventude, tratando de questões macroestruturais como desestruturação social, política e corrupção, liberdade de escolha como ofensa, violência civil e policial como solução para problemas sociais e meritocracia entre desiguais como panaceia salvacionista de mercado. Os adolescentes e jovens são vistos como protagonistas de processos sociais, culturais, políticos e econômicos, a partir da realidade nacional e internacional. Os sistemas socioeducativo e prisional, os objetivos do desenvolvimento sustentável - ODS que constam da Agenda 2030, políticas de saúde e violências têm foco, dentre outros temas. A conjuntura política do final da década de 2010 é criticada pela falta de recursos públicos para as políticas sociais, que escasseiam em nome de ajustes fiscais. Neste cenário, "a restrição drástica de horizontes possíveis de vida, é 
Quadro 2. Números temáticos da revista CSC sobre adolescência.

\begin{tabular}{|c|c|c|c|}
\hline Título & Ano & Editorial & Temáticas dos artigos \\
\hline $\begin{array}{l}\text { Saúde e Qualidade } \\
\text { de vida para } \\
\text { a Infância e } \\
\text { Adolescência }\end{array}$ & $\begin{array}{c}2007 \\
\text { v. } 12 \\
\text { n.5 } \\
\end{array}$ & $\begin{array}{l}\text { Promoção } \\
\text { da qualidade } \\
\text { de vida para } \\
\text { a infância e } \\
\text { adolescência }\end{array}$ & $\begin{array}{l}\text { Violência; uso de substâncias; saúde oral; interações mãe } \\
\text { adolescente e filho; adolescentes em conflito com a lei; aborto; } \\
\text { padrão nutricional; vacina hepatite B; deficiência de vitamina } \\
\text { A; vivência em abrigos; promoção de brincadeiras em hospitais; } \\
\text { dependência de tecnologia para sobrevivência e HIV-Aids. }\end{array}$ \\
\hline $\begin{array}{l}\text { Violência e saúde } \\
\text { mental na infância } \\
\text { e adolescência }\end{array}$ & $\begin{array}{c}2009 \\
\mathrm{v} .14 \\
\mathrm{n} .2\end{array}$ & - & $\begin{array}{l}\text { Problemas internalizantes; depressão; suicídio; transtorno de } \\
\text { estresse pós-traumático; sofrimento psíquico; prevenção de } \\
\text { violência; vulnerabilidade social; criança em situação de rua; } \\
\text { saúde mental na atenção primária; violência e resiliência. }\end{array}$ \\
\hline $\begin{array}{l}\text { Saúde da criança } \\
\text { e do adolescente: } \\
\text { saberes, prática, } \\
\text { avaliação }\end{array}$ & $\begin{array}{l}2011 \\
\text { v.16, } \\
\text { n. } 10\end{array}$ & $\begin{array}{l}\text { Saúde da criança } \\
\text { e do adolescente } \\
\text { em perspectiva }\end{array}$ & $\begin{array}{l}\text { Anemia; juventude indígena; nutrição; educação em } \\
\text { saúde; abandono; quedas; obesidade; saúde oral; atraso do } \\
\text { crescimento; qualidade de vida; atividades físicas; saúde } \\
\text { ambiental; promoção de saúde e arte; ventilação pulmonar } \\
\text { mecânica; cuidados fonoaudiológicos; violência sexual e HIV. }\end{array}$ \\
\hline $\begin{array}{l}\text { Risco e proteção } \\
\text { à saúde e bem } \\
\text { estar na infância e } \\
\text { adolescência }\end{array}$ & $\begin{array}{c}2014 \\
\text { v. } 19 \\
\text { n.3 }\end{array}$ & $\begin{array}{l}\text { Risco e proteção } \\
\text { à saúde e bem- } \\
\text { estar na infância } \\
\text { e adolescência }\end{array}$ & $\begin{array}{l}\text { Resiliência; programas de suporte familiar; competência social; } \\
\text { TEPT; violência sexual; ajustamento psicossocial; violência } \\
\text { entre namorados; violência; gravidez; homofobia; bullying; } \\
\text { minoria sexual; uso de substâncias; HIV-Aids; depressão e } \\
\text { sistema de informação sobre violência. }\end{array}$ \\
\hline $\begin{array}{l}\text { Riscos sociais e } \\
\text { proteção à saúde } \\
\text { de crianças e } \\
\text { adolescentes }\end{array}$ & $\begin{array}{c}2015 \\
\text { v. } 20 \\
\text { n.1 } \\
\end{array}$ & $\begin{array}{l}\text { Ciência \& Saúde } \\
\text { Coletiva faz } 20 \\
\text { anos, comemora } \\
\text { êxitos e tem } \\
\text { novas metas } \\
\end{array}$ & $\begin{array}{l}\text { Violência; riscos psicossociais; situação de abrigo; satisfação } \\
\text { com a vida; mortes violentas; reintegração familiar; } \\
\text { representações sociais; qualidade de vida; atividade física; } \\
\text { tentativas de suicídio; saúde oral; sexualidade e vacinação }\end{array}$ \\
\hline $\begin{array}{l}\text { Problemas sociais } \\
\text { e de saúde na } \\
\text { adolescência }\end{array}$ & $\begin{array}{l}2015 \\
\text { v.20, } \\
\text { n.11 }\end{array}$ & $\begin{array}{l}\text { Adolescência e } \\
\text { saúde coletiva: } \\
\text { entre o risco e o } \\
\text { protagonismo } \\
\text { juvenil }\end{array}$ & $\begin{array}{l}\text { Alimentação saudável; dieta; nutrição; fibrose cística; imagem } \\
\text { corporal; atividade física; saúde oral; qualidade de vida; } \\
\text { bruxismo; violência; violência sexual; violência entre parceiros } \\
\text { íntimos; embriaguez; comportamento suicida; uso de droga; } \\
\text { imagem corporal; sintomas depressivos; dor de cabeça; } \\
\text { paternidade; transtornos alimentares; bullying. }\end{array}$ \\
\hline $\begin{array}{l}\text { Protagonismo } \\
\text { de adolescentes e } \\
\text { jovens e subsídios } \\
\text { para políticas } \\
\text { públicas }\end{array}$ & \begin{tabular}{c|}
2018 \\
v. 23 \\
n.9
\end{tabular} & $\begin{array}{l}\text { Adolescência } \\
\text { e Juventude: } \\
\text { políticas públicas } \\
\text { e condições de } \\
\text { vida e saúde } \\
\text { em perspectiva } \\
\text { internacional } \\
\end{array}$ & $\begin{array}{l}\text { Acidentes de trânsito; agenda 2030; carga global de doenças; } \\
\text { Doenças sexualmente transmissíves; direitos; políticas de saúde; } \\
\text { adolescente em conflito com a lei; violência simbólica; National } \\
\text { Scholar Health Survey (PeNSE); programa de saúde escolar; } \\
\text { violência; violência escolar; anorexia nervosa; ação comunitária; } \\
\text { vida afetiva e sexual; educação em saúde e jogos; saúde oral; } \\
\text { quilombola; escoliose; violência sexual; riscos metabólicos; abrigo; }\end{array}$ \\
\hline $\begin{array}{l}\text { Desafios das } \\
\text { políticas públicas de } \\
\text { saúde para crianças } \\
\text { e adolescentes no } \\
\text { Brasil; presente e } \\
\text { futuro }\end{array}$ & $\begin{array}{c}2019 \\
\text { v.24, } \\
\text { n.2 } \\
\end{array}$ & $\begin{array}{l}\text { Crianças e } \\
\text { Adolescentes, } \\
\text { políticas de } \\
\text { austeridade e os } \\
\text { compromissos } \\
\text { da Agenda } 2030\end{array}$ & $\begin{array}{l}\text { Vacinação; peso corporal; promoção da saúde; prevenção } \\
\text { ao uso de drogas; indígenas e conflito ambiental; saúde oral; } \\
\text { saúde mental; nutrição; alimentação; quilombola; obesidade; } \\
\text { atividade física; autoestima; promoção de saúde e escola; } \\
\text { violência; embriaguez; violência entre pares. }\end{array}$ \\
\hline
\end{tabular}

o desafio que, sem apoio público, os jovens não conseguirão superar" ${ }^{24}$. O maior investimento público na infância e adolescência é demandado pelos editores.

A revista de 2019 abrange a infância e a adolescência sob o prisma das políticas públicas e dos compromissos assumidos na Agenda 2030 dos ODS, vistos como oportunidade histórica para melhorar os direitos e o bem-estar de cada criança e adolescente, especialmente os mais desfavorecidos, na garantia de um mundo saudável para meninas e meninos. A vulnerabilidades destas fases do desenvolvimento provêm do ambiente social mais amplo, das famílias e das comunidades que sofrem diretamente o impacto das políticas de austeridade e das medidas de autoridade fiscal. Temas como a elevada morbidade $\mathrm{e}$ mortalidade por agressões, maioridade penal, es- 
tatuto do desarmamento, pobreza extrema, fome, racismo precisam ser enfrentados. Ofertar saúde e educação de qualidade, promover sociedades pacíficas e inclusivas são consideradas agendas de compromissos com o presente e o futuro.

\section{Discussão}

Os resultados mostram crescimento significativo de estudos sobre adolescência na C\&SC nos últimos 25 anos, o que reflete sua robusta inserção e ascenção no campo da saúde pública. Este incremento chega a 15 vezes mais nos últimos anos em comparação com o início da publicação da revista. Interessante notar que enquanto houve aumento no número de trabalhos com foco específico na adolescência, inversamente houve redução no número de estudos que incluíam crianças e adolescentes, o que revela investimento voltado às especificidades do adolescer, tal qual encontrado em pesquisas internacionais ${ }^{25}$.

Enquanto disciplina acadêmica multidisciplinar, o estudo da adolescência emergiu a partir do final dos anos 60 com os periódicos: Youth and society (1969), Journal of youth and Adolescence (1972), Journal of Adolescence (1978), Journal of Adolescent Research (1986) e Journal of Research on Adolescence (1991). Outros periódicos especializados surgiram nas duas últimas décadas ${ }^{25}$. No Brasil, apenas a revista Adolescência \& Saúde, criada em 2004, é específica sobre o tema na área da saúde, dando relevância ao papel da C\&SC em estimular o conhecimento sobre esta fase da vida. A análise das publicações nestes últimos 25 anos mostra a vocação do tema para o enfoque multidisplinar da saúde coletiva. Despontam textos relevantes para a saúde pública dos adolescentes, como os relacionados à alimentação/nutrição, atividade física, saúde, doença e acidentes e violências.

A análise de evolução de publicações de temas no período evidencia alinhamento com a bibliografia nacional e internacional, priorizando temas como alimentação/obesidade/atividade física, uso de drogas, violência, que enfatizam aspectos de risco ${ }^{25}$. A perspectiva da desigualdade social brasileira é também destacada através das análises sobre padrão socioeconômico/renda e qualidade de vida. Nota-se o esforço interdisciplinar dos autores da área de saúde bucal em publicarem variados textos na perspectiva da saúde pública. Constata ainda a baixa frequência de reflexões sobre adolescentes em conflito com a lei, sexualidade, população LGBTI+, e questões raciais e étnicas. Um tema também pouco abordado é a relação da globalização e redes sociais virtuais no estilo de vida, no comportamento, nos valores e na saúde de adolescentes.

Apesar da pouca representatividade de resumos com a temática sobre adolescentes em conflito com a lei, este foi um dos focos do editorial de 2018 da revista C\&SC. A saúde de crianças e adolescentes privados de liberdade foi tema de editorial da revista The Lancet Child and Adolescent Health ${ }^{26}$, que ressaltou a relevância do estudo global sobre crianças privadas de liberdade realizado pelas Nações Unidas ${ }^{27}$. Outro exemplo de temáticas relevantes e emergentes é 'masculinidade', que, embora presente em apenas três resumos analisados, sendo um deles o editorial de 2015, reforça a importância dessa questão para a saúde coletiva.

No que se refere ao método, constata-se o aumento expressivo das pesquisas com metodologia quantitativa e a diminuição de artigos com triangulação metodológica. A saúde pública tem seguido predominantemente uma abordagem positivista baseada na epidemiologia. Contudo a relevância dos estudos qualitativos é ressaltada por periódicos internacionais, os quais também apontam para a dificuldade de que esses estudos sejam publicados em revistas médicas e de saúde de alto impacto ${ }^{28}$. Abordagens quantitativas e qualitativas são combinadas mas menos comumente publicadas. Autores internacionais reforçam que o uso desse tipo de estratégia de investigação é imprescindível para a compreensão de fenômenos complexos e apontam para o aumento do interesse nessa abordagem que envolve diferentes disciplinas ${ }^{29}$. Os estudos qualitativos estão presentes desde o início da publicação da C\&SC e se mantêm até hoje, trazendo contribuições importantes para o campo da saúde coletiva e mostrando o compromisso da revista com abordagens compreensivas. Quanto à combinação entre as abordagens qualitativas e quantitivas, a revista C\&SC apresenta maior volume de artigos no primeiro período, reduzindo o número de publicações nos últimos anos. Pode-se perguntar se o número de resumos reflete a quantidade real de pesquisas que combinam diferentes métodos de investigação, ou mesmo se pesquisadores dividem os artigos em qualitativos e quantitativos para a publicação.

Um dos desafios da área envolve a elaboração de políticas eficazes que alcancem equilíbrio entre os dados científicos e o pragmatismo político que satisfaça as necessidades da população ao longo da vida ${ }^{30}$. Em geral, as políticas públicas destina- 
das a esta população foram caracterizadas por práticas profissionais verticais, baseadas na lógica de que o saber técnico predomina sobre a compreensão integral do indivíduo. Esta postura coloca o adolescente numa posição de inferioridade e passividade ${ }^{19,31}$. Apesar do ECA ter reconhecido o adolescente como um sujeito de direitos, essa parcela da população ainda é pouco visualizada nas políticas públicas, desvalorizando o protagonismo de sua história ${ }^{9,10}$. Os aspectos culturais e sociais vividos por eles e as questões de gênero, que mostram diferenças nas vivências de adolescentes, frequentemente não são considerados no planejamento das ações em saúde ${ }^{19}$. As ações em saúde devem envolver serviços de saúde e escolas na perspectiva de que os adolescentes tenham voz e espaço para expor suas demandas, com escuta e acolhimento, possibilitando vínculos requeridos pela integralidade da atenção. Portanto, a oferta de atenção pelos serviços de saúde deve extrapolar as questões relacionadas às doenças (sejam de ordem física ou mental), o que se precisaria se refletir na produção acadêmica nacional.

Uma preocupação que se acentuou recentemente na C\&SC é a reflexão sobre a necessidade da adoção de políticas públicas capazes de combater e superar as desigualdades geográficas, sociais e étnicas do país e celebrar a riqueza da diversidade da fase da adolescência. Sobre esta questão, Editorial da Revista Lancet ${ }^{1}$ alerta que os aspectos econômicos, políticos, comerciais e ambientais, tão essenciais para a saúde de crianças e adolescentes, mudaram dramaticamente, introduzindo temas emergenciais como problemas climáticos, migração, conflitos crescentes, políticas e agendas que se afastam do fornecimento de redes de segurança social e redução da pobreza, exploração comercial continuada de crianças e jovens que levam a dietas pouco saudáveis e exposição a produtos de álcool e tabaco. Para a Lancet, a partir de 2020 crianças e adolescentes precisam ter atenção especial para que haja um futuro sustentável e saudável para todos ${ }^{1}$. Tal desafio se coloca não apenas para a Revista Ciência \& Saúde Coletiva, alvo das análises realizadas neste artigo, mas para a sociedade brasileira que precisa avançar na busca de conhecimento sistêmico, complexo e que se volte para os aspectos de promoção à saúde dos adolescentes, acompanhando as normativas e as leis nacionais existentes, porém ainda em fase de efetivação.

As análises apresentadas nesse capítulo foram realizadas a partir dos temas coletados nos resumos e títulos dos artigos, o que impossibilita a compreensão do artigo como um todo. Alguns temas e análises relevantes para a saúde coletiva podem ter sido apresentados no corpo do artigo e não no resumo. Essas limitações referem-se ao espaço reduzido para a escrita do resumo e as informações nele contidas.

\section{Colaboradores}

SG Assis, JQ Avanci e F Serpeloni participaram de todas as etapas do artigo.

\section{Agradecimentos}

Bolsa de Pós-doutorado Nota 10 da Faperj concedida à F Serpeloni. 


\section{Referências}

1. The Lancet. Campaign on Child and Adolescent Health. Editorial. Lancet 2020; 395(10218):89.

2. Word Health Organization (WHO). Young People's Health - a Challenge for Society. Report of a WHO Study Group on Young People and Health for All. Geneva: WHO; 1986. (Technical Report Series 731)

3. Brasil. Lei no 8.069, de 13 de julho de 1990. Dispõe sobre o Estatuto da Criança e do Adolescente e dá outras providências. Diário Oficial da União 1990; 14 jul.

4. United Nations Children's Fund (UNICEF). Situação das crianças e dos adolescentes no Brasil. [acessado 2020 Maio 25]. Disponível em: https://www.unicef. org/brazil/situacao-das-criancas-e-dos-adolescentesno-brasil

5. Bouzas ICS, Cader AS, Leão L. Gravidez na adolescência: uma revisão sistemática do impacto da idade materna nas complicações clínicas, obstétricas e neonatais na primeira fase da adolescência. Adolesc Saúde 2014; 11(3):7-21.

6. Instituto Brasileiro de Geografia e Estatística (IBGE). Pesquisa nacional de saúde do escolar 2015. Rio de Janeiro: IBGE; 2016.

7. Medrado-Dantas B. Tempo ao tempo: A gestão da vida em idade [tese]. São Paulo: USP; 2002.

8. Brasil, Ministério da Saúde (MS). Gestões e gestores de políticas públicas de atenção à saúde da criança: 70 anos de história. Brasília: MS; 2011.

9. Leão LS. Saúde do adolescente: atenção integral no plano da utopia [tese]. Recife: Fiocruz; 2005.

10. Kerbauy MTM. Políticas de Juventude: Políticas Públicas ou Políticas Governamentais? Estudos de Sociologia 2005; 19:193-203.

11. Horta NC, Sena RR. Abordagem ao adolescente e ao jovem nas Políticas Públicas de saúde no Brasil: um estudo de revisão. Physis 2010; 20(2):475-495.

12. Brasil. Ministério da Saúde (MS). Programa Saúde do Adolescente, Bases Programáticas. Brasília: MS; 1996.

13. Brasil. Ministério da Saúde (MS). Política Nacional de Atenção Integral à Saúde do Adolescente e Jovem. Brasília: MS; 2006.

14. Brasil. Ministério da Saúde (MS). Diretrizes Nacionais para atenção integral à saúde dos adolescentes e jovens na promoção, proteção e recuperação da saúde. Brasília: MS; 2010.

15. Brasil. Ministério da Saúde (MS). Saúde integral de adolescentes e jovens: orientações para a organização de serviços de saúde. Brasília: Editora do Ministério da Saúde; 2007.

16. Silva RS, Silva VR. Política Nacional da Juventude: Trajetória e desafios. Caderno CRH 2011; 24(63):663678.

17. Brasil. Portaria no 1.082 , de 23 de maio de 2014. Redefine as diretrizes da Política Nacional de Atenção Integral à Saúde de Adolescentes em Conflito com a Lei (PNAISARI), entre outras providências. Brasília. Diário Oficial da União 2014; 24 maio.

18. Jager ME, Batista FA, Perrone CM, Santos SS, Dias ACG. O adolescente no contexto da saúde pública brasileira: reflexões sobre o PROSAD. Psicol. estud. 2014; 19(2):211-221.
19. Dias ACG, Oliveira VZ. A percepção dos profissionais de saúde acerca do atendimento prestado ao adolescente. In: Dias ACG, organizador. Psicologia e Saúde: Pesquisas e reflexões. Santa Maria: UFSM; 2009. p. 6391.

20. Ercole FF, Melo LS, Alcoforado CLGC. Integrative review versus systematic review. Reme Rev Min Enferm 2014; 18(1):9-12.

21. De Paolo CA, Wilkinson K. Get your head into the clouds: Using word clouds for analyzing qualitative assessment data. TechTrends 2014; 58(3):38-44.

22. Murphy SA. How data visualization supports academic library assessment: Three examples from The Ohio State University Libraries using Tableau. College \& Research Libraries News 2015; 76(9):482-486.

23. Assis SG, Avanci JQ, Duarte C. Adolescência e saúde coletiva: entre o risco e o protagonismo juvenil. Cien Saude Colet 2015; 20(11):3296.

24. Moreira MR, Ribeiro JM, Motta JIJ, Hartz Z. Adolescência e Juventude: políticas públicas e condições de vida e saúde em perspectiva internacional. Cien Saude Colet 2018, 23(9):2782.

25. Levesque RJR. Reviews in Research on Adolescence: Genres, Trends, and Challenges. Adolescent Research Review 2016; 1(1):3-13.

26. The Lancet Child \& adolescent health. Youth without freedom. Lancet Child Adolesc Health 2020; 4(1):1.

27. Nowak M. The United Nations global study on children deprived of liberty. Seventy-fourth session. Promotion and protection of the rights of children. New York: UN; 2019.

28. Braun V, Clarke V. Novel insights into patients' life -worlds: the value of qualitative research. Lancet Psychiatry 2019; 6(9):720-721.

29. Ridde V, Sardan JPO. A mixed methods contribution to the study of health public policies: complementarities and difficulties. BMC Health Services Research 2015; 15(S3):S7.

30. Bleakley A, Ellis JA. A role for public health research in shaping adolescent health policy. Am J Public Health 2003; 93(11):1801-1802.

31. Santos CC, Ressel LB. O adolescente no serviço de saúde. Adolescência e Saúde 2013; 10(1):53-55.

Artigo apresentado em 03/06/2020

Aprovado em 03/06/2020

Versão final apresentada em 05/06/2020 